Acta Poetica $26(1-2)$

PRIMAVERA-OTOÑO

2005

\title{
Miguel de Cervantes, John Donne y una canción popular: el retrato de la dama en el corazón del amante
}

\author{
José Manuel Pedrosa
}

\begin{abstract}
Muchos poemas, tanto de tradición oral como del repertorio de los poetas de élite, desarrollan el tópico del retrato de la amada dibujado en el corazón del amante, según se puede apreciar cuando se abre el pecho del enamorado tras su muerte por amor. Petrarca, Cervantes, Lope de Vega, Moreto, John Donne y muchos más autores explotaron el motivo, en paralelo a una tradición oral que ha preservado versiones en toda España, en Hispanoamérica, en Portugal y en Brasil.

Several poems, both in oral tradition and in learned literature, develop the topic of the female's portrait engraved in her lover's heart, as can be appreciated when opening his chest after his death. Petrarch, Cervantes, Lope de Vega, Moreto, John Donne and many other authors have used this motif in written literature. So has oral tradition, as shown by preserved versions in Spain, Latin America, Portugal and Brazil.
\end{abstract}



Acta Poetica 26 (1-2)

PRIMAVERA-OTOÑO

2005

José Manuel Pedrosa

Universidad de Alcalá

Miguel de Cervantes, John Donne y una canción popular: el retrato de la dama en el corazón del amante

El tópico poético del amante que asegura o que acredita - a veces después de muerto- que lleva impreso en su ardoroso corazón el retrato de su amada ha merecido ya alguna atención por parte de la crítica literaria. Fue analizado por especialistas como Joseph E. Gillet $(1951,74)$ y Eduardo Martínez Torner (1966, núm. 231), aunque quien con mayor profundidad lo ha abordado ha sido, sin duda, Guillermo Serés (1966, 142-167), en un tratado ya clásico acerca de las teorías e interpretaciones del amor en la Edad Media y en los Siglos de Oro, en el que ha señalado, entre sus posibles antecedentes, diversos diálogos platónicos (Filebo 39b, Teeteto 191de), según los cuales la imagen de la amada es capaz de quedar impresa o dibujada en el amado. También en la Biblia (Proverbios III, 3; Jeremías XXXI, 33) está apuntada esta creencia - aunque enfocada hacia el amor divino y no hacia el humano-, que, en la Edad Media y en los siglos XVI y XVII, desarrollaron numerosos poetas, como Petrarca en su Canzoniere CXL, Jordi de San Jordi en su celebrado poema "Jus lo front port vostra bella semblança", ${ }_{1} \mathrm{o}$

${ }^{1}$ Véase al respecto Martí Riquer y Badía (1984, 168-171), con detallada información sobre el motivo de la imagen de la amada impresa en el amante. 
Pietro Aretino, aparte de muchos tratadistas (italianos, españoles y de otros lugares) que teorizaron con detalle al respecto. Entre los textos y autores españoles sobre los que han llamado la atención Serés y algunos críticos más que han partido de su estudio, como Enrico Di Pastena, ${ }^{2}$ están algunos del Cancionero general como López de Haro ("mas no me cumple vivir / porque cuando se vos pinta / en el alma congojosa / figura tanto hermosa, / sólo la muerte la despinta / y no otra cosa") o el Comendador Escrivá ("en aquel punto que os vi, / imagen en mí esculpida, / con mis ojos imprimida / dentro de mi alma os metî’), además de Garcilaso (recuérdese su célebre soneto "Escrito está en mi alma vuestro gesto..."), un autor del Cancionero gótico de Vásquez de Ávila ("En medio del corazón me pinté / vuestra figura, al vivo debujada, / y dejéla en mí tan bien sacada, / que la vuestra de ella discernir no sé. / De sobrado amor en mí os estampé: / soys ingrata y tan mal mirada, / que luego queréis, por una nonada, / vengaros de mí, porque os debujé..."), Hurtado de Mendoza ("Pero yo, que en el alma tu figura / tengo en humana forma abreviada, / tal hice retratarte de pintura / cual amor te dejó en ella estampada"), Pérez de Montalbán ("Yo muero, aunque no quisiera, / porque temo que te mate / la muerte, si muero yo, / que en mí estás, y ha de toparte"), etcétera, etcétera.

Pero ha habido muchos más autores, más versos y más prosas que desarrollaron o que recrearon esta singular y llamativa hipérbole literaria, y que merecen, sin duda, atención y revisión. Conviene, por ejemplo, hacer referencia a las viejas recreaciones de tipo devoto, muy presentes en la tradición hagiográfica antigua y medieval. Un tipo de milagro atribuido a numerosos santos presenta a éstos, en efecto, como teóforos o como cristóforos que llevaban impresos algún escrito o alguna imagen alusivos a Dios en el corazón o en alguna otra parte del cuerpo. Tal es el caso, por ejemplo, de San Ignacio de An-

${ }^{2}$ Véase su edición de Moreto (1999), nota en p. 172. 
tioquía, cuya hagiografía popularizó la Leyenda áurea (núm. 36), y que se convirtió en caso paradigmático e inspirador de otros relatos parecidos:

En algunos relatos se hace constar que San Ignacio, en medio de los suplicios a que fue sometido, no cesó de invocar el nombre de Jesucristo y que, cuando los verdugos le preguntaban por qué repetía tantas veces aquella invocación, respondía: "No puedo menos de repetir insistentemente un nombre que llevo grabado en mi corazón". En esos mismos relatos se dice que quienes reiteradamente habían oído esa respuesta, queriendo comprobar, tras la muerte del santo, si aquello era verdad, con un puñal le abrieron el costado, le extrajeron el corazón y quedaron pasmados al ver que, efectivamente, en él había una inscripción en letras de oro que decía: "Jesucristo"; y que a la vista de tan sorprendente hallazgo, numerosas personas se convirtieron al cristianismo. (Vorágine 1987, núm. 36) ${ }^{3}$

Pero donde más arraigo tuvo el tópico fue, desde luego, en la órbita de la literatura galante y amorosa. La cumbre, posiblemente, de sus recreaciones en este campo se la debemos a Miguel de Cervantes, quien, casi al final de su monumental última novela, Los trabajos de Persiles y Segismunda (IV, 1), insertó un episodio que describía el enfrentamiento, por culpa de invencibles celos amorosos, entre el duque de Nemurs y el príncipe Arnaldo. La escena estaba localizada en un bosque que se halla muy cerca de Roma, destino final del accidentado peregrinar de Auristela, Periandro y sus acompañantes. Apenas entrados en la espesura,

alzó acaso los ojos Auristela, y vio pendiente de la rama de un verde sauce un retrato, del grandor de una cuartilla de papel,

\footnotetext{
${ }^{3}$ Sobre este motivo, muy arraigado en la tradición hagiográfica multisecular, véase Tubach (1969, núm. 415). Y, sobre todo, Polo de Beaulieu (1999, 185-196). Agradezco a María Jesús Lacarra las preciosas indicaciones y materiales que me ha proporcionado al respecto.
} 
pintado en una tabla no más, del rostro de una hermosísima mujer, y reparando un poco en él, conoció claramente ser su rostro el del retrato, y admirada y suspensa, se le enseñó a Periandro.

A este mismo instante dijo Croriano que todas aquellas hierbas manaban sangre, y mostró los pies en caliente sangre teñidos.

Intrigados, los viajeros siguen el rastro de la sangre, que les lleva hasta el muy malherido duque de Nemurs, a quien limpian y alivian mientras él pronuncia estas palabras:

Bien hubieras hecho, ¡oh quienquiera que seas, enemigo mortal de mi descanso!, si hubieras alzado un poco más la mano, y dádome en mitad del corazón, que allí sí que hallaras el retrato más vivo y más verdadero que el que me hiciste quitar del pecho y colgar en el árbol, porque no me sirviese de reliquias y de escudo en nuestra batalla.

Al instante hallan los expedicionarios al otro herido, el príncipe Arnaldo, que con un hilo de voz reclama para sí la propiedad del retrato:

La primera señal que dio de vida fue probarse a levantar, diciendo: - No le llevarás, traidor, porque el retrato es mío, por ser el de mi alma; tú le has robado, y sin haberte yo ofendido en cosa, me quieres quitar la vida. (Cervantes 1992, 419-423)

El cruel enfrentamiento entre los dos nobles enamorados - que acabarán siendo trasladados a la ciudad en busca de cuidados - por causa del retrato; y, sobre todo, el hecho de que uno de ellos, Nemurs, proclame que dentro de su corazón está "el retrato más vivo y más verdadero que el que me hiciste quitar del pecho y colgar en el árbol", mientras que el otro, Arnaldo, defiende que ese retrato es "el de mi alma", convierten seguramente este episodio cervantino en el que con mayor detalle y quizás más alta inspiración desarrolló, en nuestros Siglos de Oro, el tópico literario que nos está ocupando. 
No dejó tampoco de recrearlo el gran Lope de Vega, el poeta máximo de lo amoroso, en versos como éstos de La Arcadia:

Si os pintara por ventura mi propia imaginación, tuviera más perfección vuestra divina hermosura. Porque está de suerte en ella natural, perfecta y clara, que hasta el habla os retratara porque me habláis dentro de ella; de suerte que el alma en mí me dice, viéndome ingrato, que no ha menester retrato quien me ve dentro de sí.

$(1975,208)$

También Agustín Moreto desarrolló una hipérbole galante parecida en El desdén con el desdén:

¿Tú logrando sus cariños, cuando su desdén helado, trocando efecto la causa, abrasa mi pecho a rayos? Primero, ¡viven los cielos! fueran las vidas de entrambos asumpto de mi venganza, aunque con mis propias manos sacara a Carlos del pecho donde, a mi pesar, ha entrado, y para morir con él matara en mí su retrato. ${ }^{4}$

(Moreto 1999, 106, vs. 2715-2726)

4 Véase también la interesantísima nota complementaria de p. 172. E, igualmente, la nota de Francisco Rico en su edición de Moreto (1971, 241). 
Moreto parece que fue muy aficionado al tópico, porque en otra de sus comedias, No puede ser... incluyó estos versos:

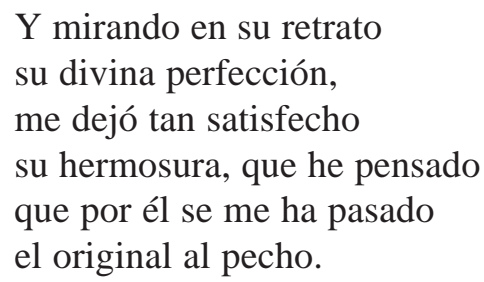

Otro ejemplo de la recreación de la vieja hipérbole de la imagen de la amada impresa en el corazón del amante lo encontramos en un alambicado romance morisco que comenzaba "Tan celosa está Adalifa / de su querido Abenámar" y que debió circular en los años de tránsito del siglo XVI al XVII:

Adalifa de mi alma,

si para satisfacerte

es menester que me abra

el pecho, donde te tengo

al natural retratada,

haré por solo tu gusto

puerta en él patente y ancha,

para que tú propia veas

si acaso no estás turbada,

cómo Abenámar te tiene

fe inviolable, afición casta.

Y si imaginas que miento,

ruego a Alá que cuando salga

al campo con el cristiano

me mate a malas lanzadas;

que jamás tenga victoria

cuando a escaramuza salga,

y que cautivo me nieguen

la libertad deseada.

(Durán 1930, I, núm. 19) 
Por su parte, el poeta y dramaturgo Miguel de Barrios, en su comedia Contra la verdad no hay fuerza introdujo también el motivo de la pintura amorosa retratada en el alma dentro de una escena en que varias figuras alegóricas disputaban por llevar consigo el albedrío:

Apetito Tened, que más que a ninguno a mí me toca llevarlo.

Verdad ¿Cómo, si mi amor consigue?

Mentira ¿Cómo, si quebró mi lazo?

Apetito Como me tiene neutral el verle tan desalmado que le pretende agarrar sin decir bueno ni malo, porque según mi opinión, ya no es de Dios ni del diablo.

Celo Pues entretanto lo lleva, que yo sabré restaurarlo.

Mentira Pues llévalo, que yo solo para quitártelo basto.

Apetito Esto de tomarlo a cuestas se me hace muy pesado.

Verdad Yo en mi corazón lo llevo.

Mentira Yo en mi alma lo retrato.

Celo Siempre sabré defenderlo.

Error Siempre sabré conquistarlo.

Apetito Pues quítenme de su carga ya que lo toman a cargo.

Mentira Así lo quiere el Estigio.

Verdad Así lo ordenan los astros.

Celo Así lo dispone el tiempo.

Error Así lo anuncian los hados.

Apetito Y así en aquesta cuestión

yo sólo salgo cargado.

(Barrios 1962, 303-304)

No sólo en la España de los siglos XVI y XVII fue un tópico 
común el del retrato encontrado en el corazón del amante. En el maravilloso poema The Damp (La miasma) de John Donne (1572-1630), el gran poeta inglés casi contemporáneo de Cervantes, se puede apreciar una de sus más elevadas recreaciones, con esa segunda estrofa que sitúa en un clima de combate temerario y de violencia suicida - como había hecho Cervantes - la desesperada queja del amante:

When I am dead, and doctors know not why, and my friends' curiosity will have me cut up to survey each part, when they shall find your picture in my heart, you think a sudden damp of love will through all their senses move, and work on them as me, and so prefer your murder, to the name of massacre.

Poor victories; but if you dare be brave, and pleasure in your conquest have, first kill the enormous giant, your Disdain, and let the enchantress Honour next be slain, and like a Goth and Vandal rise, deface records, and histories of your own arts and triumphs over men, and without such advantage kill me then.

Cuando esté muerto y no sepan los doctores el porqué y la curiosidad de mis amigos haga que me seccionen y estudien cada parte, cuando en mi corazón encuentren tu retrato, piensa que un súbito efluvio de amor discurrirá por todos sus sentidos, que, como sobre mí, sobre ellos actuará, y así elevará tu asesinato al nombre de masacre.

Pobres victorias. Pero, si osas ser valiente y obtienes placer en tu conquista, 
mata primero a ese enorme gigante, tu Desdén, y sea luego asesinado Honor, el encantador, y, cual vándalo o godo, álzate;

de tus propias artes y triunfos sobre hombres borra el recuerdo, y las historias, $y$, sin esa ventaja, dame entonces muerte.

(Donne 1996, 130-131)

No sería nada extraño que una encuesta más minuciosa pudiese ampliar de forma notable la nómina de grandes escritores que, en verso o en prosa, y en tiempos y en lugares diferentes, habrán recreado el dramático motivo del hallazgo del retrato - $\mathrm{O}$ del nombre, las letras o alguna otra seña relacionada con la amada - en el corazón o en el alma del amante. De hecho, y sin ir más lejos, al poema de Donne se le han atribuido paralelos y posibles influencias lejanas en dos strambotti italianos de Serafino de Aquila, ${ }^{5}$ lo que enlaza con el ovillo de fuentes y de recreaciones italianas a las que nos referimos al inicio de este artículo.

Pero lo que más nos interesa ahora poner de relieve a nosotros es que también ha habido otro ámbito, otro tono y otro estilo de recreación del mismo tópico que resultan cuando menos sorprendentes, si se tiene en cuenta su florecimiento siglos después de aquellos lejanos documentos, y en un terreno tan alejado del de las artificiosas quejas de tono cortesano como es el de la canción tradicional, recogida muchas veces de labios de campesinos nada o escasamente letrados en pueblos y aldeas dispersos por toda la geografía panhispánica. Son muchas, en efecto, las versiones de canciones tradicionales, recogidas en rincones muy diferentes de la tradición hispano-portuguesa, que han proyectado hacia el presente los ecos del motivo del retrato encontrado en el corazón enamorado, tal y como señaló Eduardo Martínez Torner en un estudio precursor

5 Véase al respecto la nota correspondiente de la edición de Donne citada, que remite a Guss $(1966,76)$. 
al que ya nos hemos referido, y como apreciaremos ahora nosotros a la luz de muchas más versiones.

Conozcamos la primera de ellas: la que el gran folclorista Antonio Machado y Álvarez "Demófilo" — padre de los poetas Manuel y Antonio Machado- recogió a fines del siglo XIX del repertorio flamenco de los gitanos andaluces:

Ahí tienes mi corazón;
ábrelo con esa llave,
y verás cómo aquí dentro
sólo tu persona cabe.

(Machado y Álvarez 1998, 269)

Por la misma época en que fue recogida y publicada esta letra flamenca, otro gran folclorista andaluz, Francisco Rodríguez Marín (1882-1883), dio a conocer una extensa serie de canciones tradicionales, igualmente andaluzas, relacionadas de forma más o menos cercana con nuestro tópico:

Toma este puñalito
y ábreme el pecho,
y verás tu retrato
si está bien hecho.

Tienes dos corazones;

yo no lo dudo, porque tienes el mío dentro del tuyo.

Ábreme, niña, el pecho con dos punzones y verás cómo tengo dos corazones.

Con dos agujas

y verás cómo tengo dos almas puras. 
Eché un candado en mi pecho desde que vi tu belleza,

porque ninguna entre en él sin que tú le des licencia.

A mi corazón le eché siete llaves con cadenas y al tuyo lo aprisioné para que no se me fuera.

El alma me has robado y yo, en castigo, te he metido en la cárcel del pecho mío.

Ten, pues, paciencia, porque no he de soltarte, aunque te mueras.

Mi corazón volando se entró en el tuyo; se quebraron las alas, salir no pudo.

Y está contento:

¡Como que el pobrecito se halla en su centro!

Mi corazón volando se entró en tu pecho; le cortaron las alas; se quedó dentro. Quiérelo mucho, ya que volar no puede lejos del tuyo.

Dentro de mi pecho tengo una sala de cristal $y$ una antesala de oro donde habita esa deidad. 
Toma este puñal dorado y ábreme con él el pecho, y verás una escritura que mi corazón te ha hecho.

Toma este puñal dorado y ábreme el pecho con él y en el color de la sangre verás si te quiero bien.

Toma este puñal dorado y párteme el corazón y en el color de la sangre verás si te tengo amor.

¿De qué sirve que no quieras conmigo conversación, si por más que te retires, te llevo en el corazón?

Toma allá mi corazón, con grillos, cadena y llaves; ábrelo y métete dentro, porque tú solito cabes.

Dentro de mi pecho tengo un cofre con una llave; muchos pretenden abrirlo y sólo mi amante cabe.

Desde que te vi te di la llave de mi pechito; muchos me la pretendieron y a ti te la di solito. 
Dentro de mi corazón no puedo admitir a nadie, porque tiene un candadito y mi amor tiene la llave.

Dicen que el águila es reina de todas las aves y tú solamente tienes de mi corazón la llave.

Ya se cerró mi pecho; toma la llave, y hasta que tú no vuelvas, ya no se abre.

¿Qué friolera, que mi pecho se abriese para cualquiera!

Ábreme el pecho y registra hasta el último rincón, y verás cómo tú reinas donde ninguno reinó.

Toma esta rosa encarnada y ábrela, que está en capullo, y verás mi corazón enlazado con el tuyo.

Toma esta llave dorada $\mathrm{y}$ abre este fuerte castillo y verás mi corazón entre cadenas y grillos.

Entre grillos y cadenas tengo yo mi corazón; entre cadenas y grillos, como si fuera un ladrón. 


\begin{abstract}
Ahí tienes mi corazón entre dos flechas metido y para mayor dolor, entre cadenas y grillos.

Tengo en el pecho escritas tus falsedades; tengo de publicarlas, aunque te enfades.

Pues no creyera

que me hubieras vendido de tal manera.
\end{abstract}

En otros lugares de la geografía española se han recogido canciones del mismo tipo. Véanse las siguientes - casi idénticas-, castellana y aragonesa, respectivamente:

Toma, niña, este puñal
y ábreme por el costado
y verás mi corazón
de quién está enamorado.

(Vergara 1912, 101)

Toma, niña, este puñal y ábreme por el costado, verás en mi corazón de quién está enamorado.

(Palay Sampietro 1990, 20)

También en Hispanoamérica se han documentado canciones que desarrollan tópicos parecidos. Las siguientes son versiones argentinas:

Toma este puñalito, abrime el pecho 
y verás tu retrato

si está bien hecho.

Si está bien hecho, sí, abrilo, abrilo;

no te demores, mi alma, en descubrilo.

(Carrizo 1933, 705) ${ }^{6}$

Toma este faconcito

y abrime el pecho,

ahí verás tu retrato

si está bien hecho.

Si está bien hecho, sí, y ansí decile

a la dueña de mi alma

que no me olvide.

(Furt 1924, 71)

Si supieras penetrar

en el fondo de mi pecho, verías cómo tu nombre

está grabado allí dentro.

(Carrizo 1933, 358)

Con tus hermosos ojos

abrime el pecho,

ai verás tu retrato

si está bien hecho.

(Draghi Lucero 1938, 402)

Ahí tienes mi corazón, abrilo con esta llave, para que veas que adentro sólo tu persona cabe.

(Ochoa de Masramón 1966, 122)

\footnotetext{
${ }^{6}$ Una versión parecida fue editada en Carrizo (1926, 173).
} 
A continuación conoceremos algunas canciones mexicanas y venezolanas que desarrollan la muy arraigada hipérbole:

Toma esta llavita de oro, abre mi pecho y verás lo mucho que yo te quiero y el mal pago que me das.

Descorre todos sus velos, mira lo que lleva dentro: lleva amores, lleva celos y un poco de sentimiento.

(Frenk 1975-1985, núm. 3225b)

Toma, niña, este puñal y abrime por un costado pa que veas mi corazón con el tuyo retratado.

(J. Lezcano, Poesía popular venezolana no. 50, apud Martínez Torner 1966, núm. 231)

Allá te mando un platillo de yerbabuena florido; entre cogollo y cogollo va mi corazón partido.

(Ramón y Rivera 1988, 309)

En la tradición oral portuguesa abundan también este tipo de canciones. He aquí algunas muestras, tomadas todas ellas de una colección que fue recogida en el Baixo-Alemtexo en los años finales del siglo XIX:

Abre meu peito, verás dois raminhos feloridos, e no meio encontrarás nossos corações unidos. 
Aqui tens meu coração, se o queres matar, podes;

olha que estás dentro d'elle: se o matas, tambem morres!

Abre meu lado esquerdo, verás meu coração morto, verás, as tuas saudades, em que estado me têm posto.

A carta que me mandaste, abri-a com muito geito; trazia teu coração: caiu-me dentro do peito.

Apalpei meu lado esquerdo, achei meu coração morto: olha, a tua saudade, em que estado me tem posto!

A penna com que te escrevo não é de nenhum pavão; e' creada e nascida dentro do meu coração.

Apalpei meu lado esquerdo, não achei meu coração; mas tive a feliz noticia que estava na tua mão.

(Dias Nunes 1900, 29-32)

Eu hei-de abrir e fechar uma janella em teu peito, para vêr de que maneira o teu coração 'stá feito. 
Eu tenho meu coração em quatro boccados feito: corre sangue a borbotões d'este meu sincero peito!

Eu senti ranger meu peito, metti a mão de vagar: achei meu coração morto... sem o sentir acabar!

Fui colher a rosa branca a' roseira do Japão: era o teu fiel retrato unido ao meu coração.

(Dias Nunes 1901, 78-80).

La siguiente es una versión que ha sido documentada en la tradición oral de Brasil:

\begin{abstract}
Amo-te como presente em longa separação; acharás teu nome escripto dentro do meu coração.
\end{abstract}

(Sylvio Romero, II, p. 53, apud Martínez Torner 1966, 231)

El tópico ha conocido derivaciones curiosas en la tradición oral moderna. Así, en una versión del romance tradicional de La novia abandonada del duque de Alba que fue recogida por mí en Cañamero (Cáceres) se explicaba que, tras la muerte de amor (despreciada por el noble) de la desdichada joven,

médicos y cirujanos, todos están en porfía;

trataron de abrirla el pecho, por ver de lo que moría.

Y al lado del corazón tres letras de oro tenía, que en la una decía Duque, y en la otra Duque de mi vida... ${ }^{7}$

\footnotetext{
${ }^{7}$ La versión fue recogida el 8 de diciembre de 1990 al señor Agustín Barba
} (nacido en aquel pueblo en 1924). 
También en una canción narrativa vulgar, o de ciego, que ha sido recogida en tierras manchegas, un mensaje de este tipo, aparecido en el pecho de la víctima, servía para denunciar al asesino:

En el pecho lleva un ramo de azahar, con un letrero que dice:

Me ha matado un criminal.

(Vallejo Cisneros 1988, 159)

El último texto que vamos a conocer es tan interesante como significativo, porque nos devuelve al ámbito de la primera documentación escrita que habíamos conocido de este tipo de poema, en la pluma de escritores de élite que gustaron desarrollarlo y adornarlo con las galas de su ingenio y de su estilo. Esta vez es el gran poeta andaluz Manuel Machado quien lo reformuló en una de las estrofas popularizantes, directamente inspirada en la tradición flamenca andaluza, de su Cante hondo (1912):

Si mi corazón se abriera

lo mismo que una graná,

en $c a$ uno de sus granitos

te verías retratá.

(Machado 1993, 237)

Como hemos podido comprobar, la productividad de un tópico argumental tan específico como es el que nos ha ocupado puede arrojar resultados y conclusiones fascinantes sobre la producción, la transmisión, la esencia de la canción tradicional, y, sobre todo, sobre las fronteras, ciertamente borrosas, y hasta muy permeables a veces, que la separan de la poesía escrita (Petrarca, Donne, Lope, Manuel Machado, etc., etc., etc.) e incluso de la prosa más sofisticada (como la del Persiles cervantino). La documentación, a lo largo de muchos siglos y en 
tradiciones muy diferentes, de la impactante hipérbole amorosa del retrato encontrado en el corazón del amante no sólo nos permite apreciar, como tantas otras veces, la enorme capacidad viajera, la potencia migratoria, la proverbial resistencia al silencio y al olvido de la canción tradicional, sino también explorar las metamorfosis estilísticas que puede a veces sufrir (entre los polos del tono más artificioso y del más llanamente popular), cuando no los trasvases de un género a otro, de una órbita de producción y de transmisión (de la oral a la escrita, y viceversa) diferentes, $\mathrm{y}$ - en definitiva - de una galaxia literaria a otra.

\section{REFERENCIAS}

BArrios, Miguel de, 1962. "Contra la verdad no hay fuerza", en $\mathrm{La}$ poesía religiosa de Miguel de Barrios, K. R. Scholberg (ed.), Madrid-Ohio, State University Press, pp. 249-341.

Carrizo, Juan Alfonso, 1933. Cancionero popular de Salta, Buenos Aires, A. Baiocco.

—, 1926. Antiguos cantos populares argentinos, Buenos Aires, Silla Hermanos.

Castillo, Hernando del [1511], 1958. Cancionero general, Antonio Rodríguez Moñino (ed.), Madrid, Real Academia Española.

Cervantes, Miguel de, 1992. Los trabajos de Persiles y Segismun$d a$, J. B. Avalle-Arce (ed.), Madrid, Castalia.

Dias Nunes, M., 1997. "Cancioneiro popular do Baixo-Alemtejo. Primeira Parte", A tradição: Revista Mensual d'Ethnographia Portugueza, Illustrada, Serpa, Câmara Municipal, reed. facs. Año III, vol. 3 (1900), 29-32 y (1901), 78-80.

Donne, John, 1996. Canciones y sonetos, P. Ribes (ed.), Madrid, Cátedra.

Draghi Lucero, Juan, 1938. Cancionero popular cuyano, Mendoza, Best Hermanos.

DuRÁn, Agustín, 1930. Romancero general o colección de romances castellanos, anteriores al siglo XVIII, reed., Madrid, Librería y Casa Editorial Hernando. 
Frenk, Margit et al., 1975-1985. Cancionero folklórico de México, 5 vols., México, El Colegio de México.

FurT, Jorge M., 1924. Arte gauchesco: motivos de poesía, Buenos Aires, Coni.

Gillet, Joseph E., 1951. Propalladia and Other Works by Bartolomé de Torres Naharro, Bryn Mawr, Menasha George Banta Publishing Co., Pennsylvania, vol. III.

Guss, Donald L., 1966. John Donne, Petrarchist: Italianate Conceits and Love Theory in the Songs and Sonnets, Detroit, Wayne State University Press.

Machado, Manuel, 1993 [1912]. Poesías completas, A. FernándezFerrer (ed.), Sevilla, Renacimiento.

Machado y Álvarez, Antonio, 1998. Cantes flamencos y Cantares, E. Baltanás (ed.), Madrid, Espasa Calpe.

MARTínEz Torner, Eduardo, 1966. Lírica hispánica: relaciones entre lo popular y lo culto, Madrid, Castalia.

Moreto, Agustín, 1999. El desdén con el desdén, Barcelona, Crítica.

—, 1971. El desdén con el desdén. Las galeras de la honra. Los oficios, F. Rico (ed.), Madrid, Castalia.

—, 1950. "No puede ser...", en Comedias escogidas [1911], L. Fernández-Guerra y Orbe (ed.), reed., Madrid, Atlas, pp. 187-208 (Biblioteca de Autores Españoles, 39).

Ochoa de Masramón, Dora, 1966. Folklore del Valle de Concarán, Buenos Aires, Luis Lasserre \& Cía.

Palay Sampietro, Miguel, 1990. Coplas, gentes y relatos de la Ribera del Cinca, Terrassa, Ègara.

Polo de Beaulieu, Marie-Anne, 1999. "La légende du coeur inscrit d'Ignace dans la littérature religieuse et didactique", en Éducation, prédication et cultures au Moyen Âge. Essais sur Jean Gobi le Jeune, Lyon, Presses Universitaires, pp. 185-196.

RAMÓN y RIVERA, Luis Felipe, 1988. La poesía folklórica de Venezuela, Caracas, Monte Ávila.

Riquer, Martí de, y Lola BAdía, 1984. Les poesies de Jordi de Sant Jordi, Valencia, Tres Quatre.

Rodríguez Marín, Francisco, 1882-1883. Cantos populares españoles, 4 vols., Sevilla, Francisco Álvarez y Cía.

SERÉs, Guillermo, 1966. La transformación de los amantes. Imágenes del amor de la Antigüedad al Siglo de Oro, Barcelona, Crítica. 
Tubach, Friedrich C., 1969. Index Exemplorum: A Handbook of Medieval Religious Tales, Helsinki, Suomalainen TiedeakatemiaAcademia Scientiarum Fennica (Folk Fellow Communications, 204).

Vallejo Cisneros, Antonio, 1988. Música y tradiciones populares, Ciudad Real, Diputación.

Vega, Lope de, Félix, 1975. La Arcadia, E. S. Morby (ed.), Madrid, Castalia.

Velázquez de Ávila, 1951. Cancionero gótico, Antonio Rodríguez Moñino (ed.), Valencia, Castalia.

Vergara, Gabriel Ma $\mathrm{M}^{\mathrm{a}}$ 1912. Cantares populares recogidos en diferentes regiones de Castilla la Vieja y particularmente en Segovia y su tierra, Madrid, Establecimiento Tipográfico de Fortanet.

Vorágine, Santiago de la, 1987. La leyenda dorada, Fray J. M. Macías (tr.), 2 vols., Madrid, Alianza. 